\title{
Evaluation of ceftaroline and levofloxacin against Staphylococci using serum from patients with community- Acquired pneumonia
}

\author{
Gary E. Stein ${ }^{1 *}$, Curtis L. Smith ${ }^{2}$, Amy E. Scharmen ${ }^{1}$ and Daniel H. Havlichek ${ }^{1}$ \\ ${ }^{1}$ Department of Medicine, Michigan State University, East Lansing, Michigan, USA \\ ${ }^{2}$ College of Pharmacy, Ferris State University, Lansing, MI, USA
}

\begin{abstract}
Purpose: Currently, no clinical data exists comparing ceftaroline to a "respiratory" fluoroquinolone in patients with community-acquired bacterial pneumonia (CABP). The purpose of this study was to compare time-kill assays of ceftaroline and levofloxacin against clinical isolates of Staphylococcus aureus using sera from hospitalized patients with a diagnosis CABP.
\end{abstract}

Methods: A total of 12 patients were equally randomized to receive ceftaroline ( $600 \mathrm{mg}$ q12h) or levofloxacin (750 mg q24h) for treatment of presumptive CABP Blood samples were obtained on day 3 at 2, 6 and 12h after the initiation of the antibiotic infusion and serum levels were measured using a LC/MS/MS assay. Time-Kill curves were performed using these patient sera against selected clinical isolates of S. aureus with levofloxacin $\mathrm{MICs}$ ranging from $0.5 \mathrm{mg} / \mathrm{L}$ to $4 \mathrm{mg} / \mathrm{L}$.

Findings: Both agents exhibited bactericidal activity ( $\geq 3 \log$ kill at $24 \mathrm{~h}$ ) against methicillin-sensitive S. aureus (MSSA) strains with levofloxacin MICs=0.5 and $1.0 \mathrm{mg} / \mathrm{L}$. Only ceftaroline produced bactericidal activity against MSSA isolates with levofloxacin MICs=2.0 and $4.0 \mathrm{mg} / \mathrm{L}$. Similar results were observed against methicillin-resistant S. aureus (MRSA) strains for levofloxacin but bactericidal activity was not observed for ceftaroline against all MRSA isolates. Bacterial regrowth was observed with 6 and $12 \mathrm{~h}$ serum samples against MRSA strains with ceftaroline MICs $>0.25 \mathrm{mg} / \mathrm{L}$.

Implications: In summary, our study results found that clinical concentrations of ceftaroline exhibited bactericidal activity against strains of S. aureus that were both susceptible as well as non-susceptible to levofloxacin, but did not produce bactericidal activity against all strains of MRSA.

\section{Introduction}

The etiology and treatment of pneumonia has been studied for over a hundred years [1]. Despite ongoing research and the development of newer antibiotics, this infection continues to be a major cause of patient morbidity and mortality. Although Streptococcus pneumoniae remains the most commonly identified cause in hospitalized patients with community-acquired bacterial pneumonia (CABP), its frequency has declined over the past 20 years while Staphylococcus aureus has increased [2]. Moreover, S. aureus is the most commonly isolated pathogen from respiratory cultures in patients with influenza and bacterial coinfection [3].

Current guidelines for empirical antimicrobial therapy for noncritically ill hospitalized patients with CABP recommend a betalactam (ampicillin, ceftriaxone, etc.) plus a macrolide or a respiratory fluoroquinolone [4]. Neither of these therapeutic regimens is ideal for the treatment of staphylococcal infections, especially with the emergence of methicillin-resistant strains in patients hospitalized with pneumonia [2]. Levofloxacin is the most commonly used respiratory fluoroquinolone in U.S. acute care hospitals for community-acquired lower respiratory tract infections [5]. One concern with the empiric use of levofloxacin for serious CABP infections is that its activity against $S$. aureus has diminished over the past decade and has susceptibility rates of $89 \%$ and $31 \%$, respectively, against contemporary U.S. clinical isolates of methicillin-sensitive (MSSA) and methicillin-resistant (MRSA) strains of S. aureus [6]. Similar susceptibility rates have also been observed in S. aureus isolates from European medical centers [7]

Ceftaroline is a new parenteral cephalosporin with antimicrobial activity against multidrug-resistant gram-positive bacteria, including $S$. aureus strains with reduced susceptibility to beta-lactams and respiratory fluoroquinolones [8]. This new antibioitic was approved for the treatment of CABP based upon clinical trials of ceftaroline versus ceftriaxone [9]. In these trials, ceftaroline provided higher clinical cure rates in patients with infections due to MSSA [10]. Patients with infections due to MRSA were excluded from these studies.

Currently, there are no clinical outcome studies of ceftaroline versus a "respiratory" fluoroquinolone in patients with CABP. Due to this lack of clinical data, we conducted a preliminary pharmacokinetic (PK) and pharmacodynamic (PD) study of ceftaroline and levofloxacin in hospitalized patients with presumptive CABP. The objective of this ex vivo PD investigation was to analyze and compare the bactericidal activity of ceftaroline to levofloxacin against selected strains of MSSA

Correspondence to: Gary E. Stein, Department of Medicine, Michigan State University, East Lansing, MI, 48824 USA, Tel: 517-353-5126; Fax: 517-353-1922; E-mail: Gary.Stein@hc.msu.edu, steing@msu.edu

Key words: ceftaroline, community-acquired pneumonia, pharmacokinetics, time-kill

Received: July 04, 2016; Accepted: July 25, 2016; Published: July 28, 2016 
and MRSA.

\section{Patients and methods}

Adult patients admitted to the hospital with a diagnosis of CABP were eligible to enroll into this study. Patients with renal or hepatic failure, pregnant, or admitted to the intensive care unit were excluded from this trial. Enrolled patients were equally randomized to receive an intravenous infusion of levofloxacin $(750 \mathrm{mg})$ every 24 hours or ceftaroline $(600 \mathrm{mg})$ every 12 hours for treatment of their infection. Each subject gave written informed consent that was approved by the hospital research review committee before entry into this investigation.

\section{Blood samples}

Blood samples were obtained from each patient following the third dose of antibiotic treatment at 2 hours, 6 hours, and 12 hours after initiation of the infusion. After centrifugation, serum samples were aliquoted and stored at $-70^{\circ} \mathrm{C}$ until time of analysis. The serum concentrations of levofloxacin and ceftaroline were measured by a validated Turbo Inospray liquid chromatography-tandem mass spectrometry (LC/MS/MS) assay developed by Keystone Bioanalytical Corporation (North Wales, PA) [11]. This method uses protein precipitation by methanol to isolate the analytes from plasma. Following protein precipitation, the supernatant is further diluted with a solution of ammonium formate in water. The entire extraction is performed rapidly (less than 90 minutes) and in an ice-bath to minimize degradation or conversion of the analytes. A $50-\mu \mathrm{L}$ sample volume is used and a deuterated (d3) form of each analyte is used as the respective internal standards. Precision and accuracy of the method was established based on five batches run over at least a three day period. Each precision and accuracy batch contained six replicate quality controls samples at four concentration levels. Precision and accuracy was also established at the lower limit of quantification. The inter-assay coefficient of variation for the quality controls ranged from 2.14-3.3\%.

\section{Pharmacokinetics}

The PK parameters of ceftaroline and levofloxacin were calculated from the three serum samples for individual subjects using standard noncompartmental methods with Phoenix WinNonlin Version 6.3 (Pharsight Corporation, Cary, NC). Parameters were calculated at steady state using the area under the curve (AUC) and area under the first moment curve (AUMC) from the time of dosing to the time of the last observation for serum. Clearance $(\mathrm{Cl})$ was calculated as dose/ $\mathrm{AUC}_{\text {serum }}$. Volume of distribution at steady state (Vss) was calculated as (dose.AUMC ${ }_{\text {serum }}$ )/AUC ${ }_{\text {serum }}{ }^{2}$. The elimination rate constant $(\mathrm{k})$ and half-life $\left(\mathrm{T}^{1} 1 / 2\right)$ were derived using $\mathrm{Cl} / \mathrm{Vss}$ and $0.693 / \mathrm{k}$, respectively.

\section{Bacterial isolates}

Clinical isolates of S. aureus (Table 1) were obtained from JMI Labs (North Liberty, IA). These strains were chosen to represent a range of current clinical isolates. The minimum inhibitory concentrations (MICs) for these bacteria were determined by both microbroth dilution and $\mathrm{E}$ test methodology according to the Clinical Laboratory Standards Institute (CLSI) [12].

\section{Time-kill curves}

Serum samples were tested against each $S$. aureus isolate by a modification of the time-kill method described in the CLSI guidelines [13]. Two hundred twenty-five microliters of each serum sample was plated on microtiter plates and inoculated with bacterial strains. To prepare the inoculum, staphylococcus colonies were suspended in cation-supplemented Mueller-Hinton broth. Twenty-five microliters of inoculum were used to inoculate each serum sample. Viability counts of each culture were carried out at $0,2,6$ and 24 hours after inoculation. Sampling was done by removing a $5-\mu \mathrm{L}$ aliquot from each sample and serially diluting it 10 -fold in media to minimize antibiotic carryover. Ten microlitre aliquots of both the undiluted and diluted samples were plated on Mueller-Hinton plates and colonies counted after 24 hours of incubation at $35^{\circ} \mathrm{C}$. Time-kill assays were analyzed by determining the number of bacteria $\left(\log _{10} \mathrm{cfu} / \mathrm{mL}\right)$ at 2,6 and 24 hours, compared with counts at 0 hour. The range of quantification was $20-200 \mathrm{cfu} / \mathrm{mL}$. Growth controls were included in each experiment. Geometric means of bacterial concentrations $\left(\log _{10} \mathrm{cfu} / \mathrm{mL}\right)$ were used to determine the difference in log-kill at 24 hours. Bactericidal activity was defined as a reduction of the original inoculum by $\geq 3 \log \mathrm{cfu} / \mathrm{mL}$ (99.9\%) at $24 \mathrm{~h}$.

\section{Results}

Twelve patients were enrolled into this study. Six subjects ( 2 males) received levofloxacin and had an age range of 26 to 72 years (mean, 56 years) and total body weights of 73 to $123 \mathrm{Kg}$ (mean, $102 \mathrm{Kg}$ ). Six (1 male) subjects received ceftaroline and had an age range of 40 to 61 years (mean, 52 years) and total body weights of 68 to $132 \mathrm{Kg}$ (mean, $102 \mathrm{Kg}$ ). The mean creatinine clearance in the levofloxacin and ceftaroline groups was $87 \mathrm{~mL} / \mathrm{min}$ and $100 \mathrm{~mL} / \mathrm{min}$, respectively. None of these patients required dosage adjustment of their antibiotic nor had an adverse effect associated with these agents.

The mean serum concentrations from our patients are similar to those previously reported [11]. The mean \pm standard deviation (SD) pharmacokinetic parameters displayed in Table 2 were derived from the serum samples obtained from these subjects.

The bacteria utilized in our time-kill experiments included a MIC range $(0.5-4 \mathrm{mg} / \mathrm{L})$ of $S$. aureus isolates to levofloxacin (Table 1 ). Interpretive criteria from the CLSI are: MICs $\leq 1.0 \mathrm{mg} / \mathrm{L}$ (susceptible), MICs=2.0 mg/L (intermediate), and MICs $\geq 4.0 \mathrm{mg} / \mathrm{L}$ (resistant) for Staphylococcus spp. to levofloxacin [14]. All of these isolates were

Table 1. The MICs (mg/L) of S. aureus isolates tested in this study.

\begin{tabular}{|l|c|c|c|}
\hline Isolate No. & Year & Levofloxacin & Ceftaroline \\
\hline Methicillin-Sensitive Strains & \multicolumn{2}{|c|}{} \\
\hline 24280 & 2013 & 0.5 & 0.125 \\
\hline 46537 & 2013 & 1.0 & 0.19 \\
\hline 3015 & 2013 & 2.0 & 0.094 \\
\hline 12367 & 2013 & 4.0 & 0.094 \\
\hline Methicillin-Resistant Strains & & \\
\hline 15041 & 2013 & 0.5 & 0.25 \\
\hline 27345 & 2013 & 1.0 & 0.5 \\
\hline 2696 & 2013 & 2.0 & 0.38 \\
\hline 27708 & 2013 & 4.0 & 0.25 \\
\hline
\end{tabular}

Susceptible isolates have a MIC $\leq 1.0 \mathrm{mg} / \mathrm{L}$ for both levofloxacin and ceftaroline

Table 2. Mean (SD) Pharmacokinetic parameters in the two Patient groups.

\begin{tabular}{|l|c|c|}
\hline Parameter & Ceftaroline $(\mathbf{n}=\mathbf{6})$ & Levofloxacin $(\mathbf{n}=\mathbf{6})$ \\
\hline Serum concentrations $\mathbf{( m g / L )}$ & & \\
\hline $\mathbf{- 2 h}$ & $19.9(4.3)$ & $8.5(1.5)$ \\
\hline $\mathbf{- 1 2 h}$ & $1.0(0.2)$ & $3.4(1.1)$ \\
\hline $\mathbf{T} 1 / \mathbf{2}(\mathbf{h})$ & $1.9(0.2)$ & $7.2(1.4)$ \\
\hline Vd $(\mathbf{L})$ & $20.6(5.2)$ & $92(15)$ \\
\hline AUC $(\mathbf{m g} \cdot \mathbf{h} / \mathbf{L})$ & $90(15)$ & $87(23)$ \\
\hline $\mathbf{C l} \mathbf{( L / h )}$ & $7.3(1.5)$ & $9.4(3.1)$ \\
\hline
\end{tabular}


found to be susceptible (MICs $\leq 1.0 \mathrm{mg} / \mathrm{L}$ ) to ceftaroline based on CLSI criteria.

Peak (2h) levofloxacin concentrations were tested for bactericidal activity due to the concentration-dependent nature of this antimicrobial. These concentrations exhibited bactericidal activity (reduction in bacterial density of at least $3 \log _{10} \mathrm{cfu} / \mathrm{mL}$ at $24 \mathrm{~h}$ ) against levofloxacin susceptible strains of $S$. aureus (Figures 1 and 2). Bactericidal activity

A.

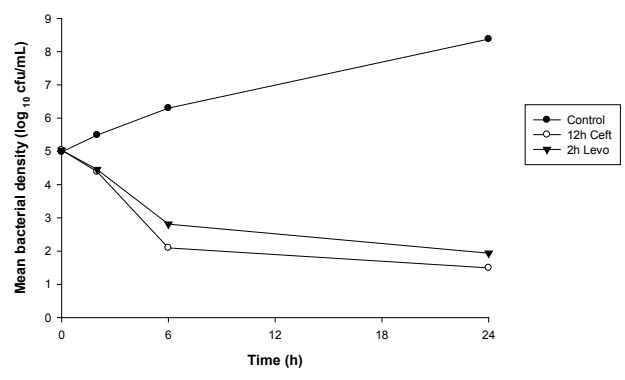

B.

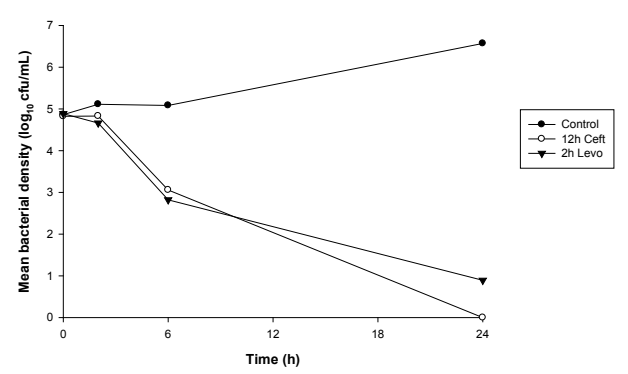

C.

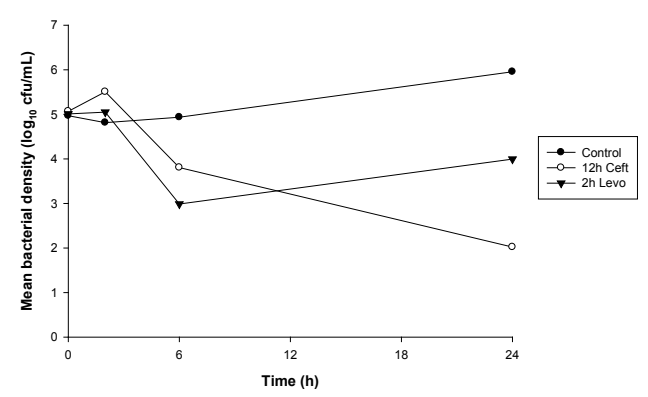

D.

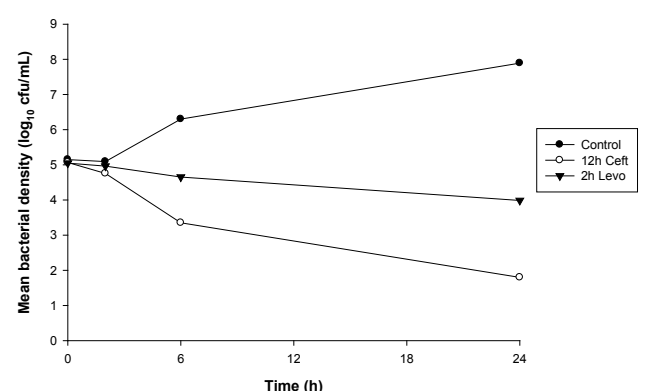

Figure 1. Time-kill curves against MSSA isolates.Data are plotted as means $(n=6)$ of bacterial densities over 24h.(A) MSSA 24280; (B) MSSA 46537; (C) MSSA 3015; (D) MSSA 12367. was not observed for levofloxacin against the intermediate or resistant isolates. A reduction of $\leq 1 \log _{10} \mathrm{cfu} / \mathrm{mL}$ at 24 hours was observed for these strains. Bactericidal activity was observed for ceftaroline, a timedependent antimicrobial agent, including trough $(12 \mathrm{~h})$ concentrations, against each of the MSSA isolates tested in this study (Figure 1). In contrast, ceftaroline did not exhibit bactericidal activity against all the MRSA strains at each time point. Regrowth at $24 \mathrm{~h}$ was observed for

\section{A.}

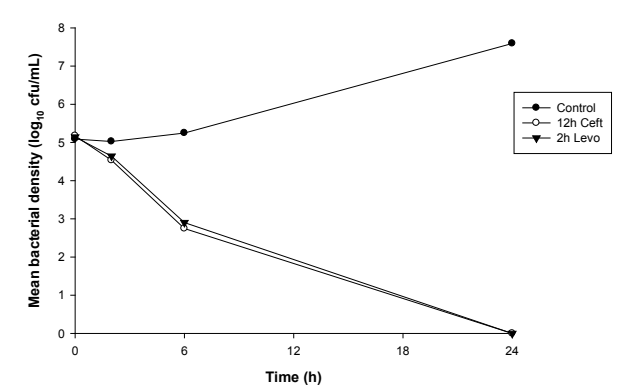

B.

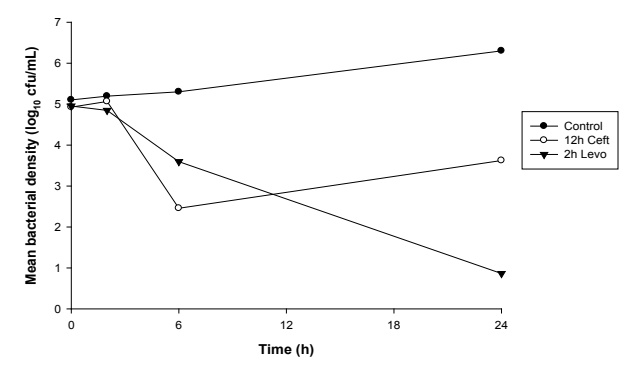

C.

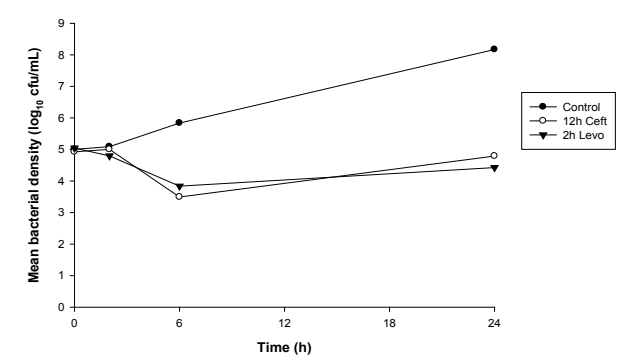

D.

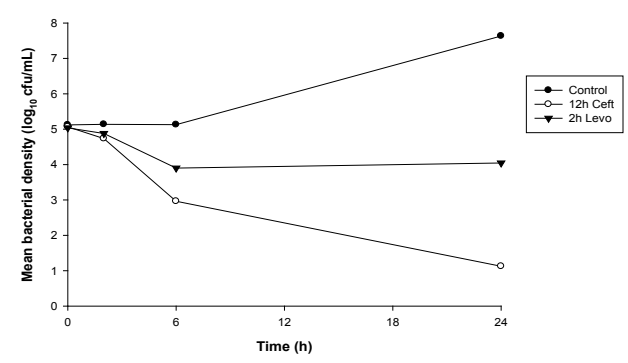

Figure 2. Time-kill curves against MRSA isolates.Data are plotted as means $(n=6)$ of bacterial densities over 24h.(A) MRSA 15041; (B) MRSA 27345; (C) MRSA 2696; (D) MRSA 27708. 
MRSA isolates with MICs $>0.25 \mathrm{mg} / \mathrm{L}$ with $6 \mathrm{~h}$ and $12 \mathrm{~h}$ serum samples. The $12 \mathrm{~h}$ time kill curves are exhibited in figure 2.

\section{Discussion}

The demographics of our patients were found to be comparable to subjects previously enrolled into CABP clinical trials of ceftaroline with the exception that this study had a higher ratio of female patients [9]. Moreover, the PK parameters derived from these patients were found to be similar to those previously published for these antimicrobials [1517]. Both levofloxacin and ceftaroline are primarily eliminated by the kidneys and have low protein binding.

Although both of these antibiotics can exhibit bactericidal activity, the PD goals for levofloxacin and ceftaroline are dissimilar. Levofloxacin and other fluoroquinolones display concentrationdependent antimicrobial activity. Both Peak/MIC and AUC/MIC ratios have been shown to be predictors of outcome for these agents [18]. In fluoroquinolone in vitro and animal models of $S$. aureus infection, drug AUC/MIC ratios of $>30$ were found to be good predictors of a microbiological cure [19]. Since levofloxacin is $\sim 30 \%$ protein bound in blood, our patients would have a mean free drug AUC of approximately 60. Thus, levofloxacin should not provide bactericidal activity against $S$. aureus isolates with MIC $\geq 2.0 \mathrm{mg} / \mathrm{L}$ (AUC/MIC $\leq 30$ ). This was observed in our serum time-kill experiments. The levofloxacin timekill curves exhibited a lack of bactericidal activity against $S$. aureus isolates with MICs $\geq 2.0 \mathrm{mgL}$.

In contrast to the fluoroquinolones, the cephalosporin antibiotics exhibit time-dependent (concentration-independent) antimicrobial activity. In PD models, the amount of time in which free drug concentrations exceed the MIC ( $\mathrm{fT}_{\mathrm{MIC}}$ ) of an organism is the best predictor of bacterial killing [20]. Near-maximal bactericidal effects require $60 \%-70 \% \mathrm{~T}>\mathrm{MIC}$ for older cephalosporins. In an in vitro PD model, a $\mathrm{fT}_{\mathrm{MIC}}$ of $92 \%$ was found to be bactericidal ( $\geq 3$ log killing) for ceftaroline against strains of MRSA with MICs $\leq 1.0 \mathrm{mg} / \mathrm{L}$ [21]. No bacterial regrowth occurred during the 24 hour study period. MacGowan et al. also found that $\mathrm{fT}_{\text {MIC }}>50 \%$ was necessary to suppress the emergence of resistance in an in vitro $\mathrm{PK}$ model of $S$. aureus infection [22]. In a study of human-simulated epithelial lining fluid exposures of ceftaroline, an enhanced dosing regimen (600 mg q8h) was needed to provide bactericidal activity over $72 \mathrm{~h}$ against MRSA with MICs $\geq 0.5 \mathrm{mg} / \mathrm{L}$ [23]. In our ex vivo study, we did not observe bactericidal activity with ceftaroline serum concentrations at $6 \mathrm{~h}$ and $12 \mathrm{~h}$ against MRSA strains with MICs $>0.25 \mathrm{mg} / \mathrm{L}$.

Serum time-kill curves are a rational approach to describe drugbacteria interactions [24]. This model integrates antimicrobial activity with PK parameters in human subjects. Furthermore, this time-kill analysis occurs in the presence of factors such as antibodies, complement and protein binding, as well as clinically relevant drug concentrations. The strains selected for our experiments represents a range of current clinical isolates of $S$. aureus (levofloxacin $\mathrm{MIC}_{50}=0.25 \mathrm{mg} / \mathrm{L} ; \mathrm{MIC}_{90} \geq 4.0 \mathrm{mg} / \mathrm{L}$ ) $[6,7]$. Our findings further support the susceptibility breakpoint (MIC $=1.0$ $\mathrm{mg} / \mathrm{L}$ ) for levofloxacin against Staphylococcus spp [14]. We observed bactericidal activity with levofloxacin against susceptible isolates, but not against the intermediate or the resistant strains. All of the tested S. aureus isolates were susceptible to ceftaroline but serum bactericidal activity was dependent upon the time and the MIC of the strain of S. aureus.

\section{Conclusion}

In summary, the increasing resistance observed in S. aureus to levofloxacin engenders concern regarding the use of this antibiotic for empiric treatment of serious staphylococcal infections, including CABP. Resistant isolates to ceftaroline were uncommon in surveillance studies of U.S. and European medical centers [7,25]. Furthermore, we found that this cephalosporin exhibits prolonged bactericidal activity in serum from patients with pneumonia against susceptible as well as non-susceptible strains of $S$. aureus to levofloxacin. The most appropriate dosing regimen of ceftaroline for serious MRSA infections where a bactericidal effect is required warrants further study [26].

\section{Acknowledgements}

The authors thank Ali Al Arab, MD for his help in enrolling patients into this study.

\section{Funding}

This study was supported in part by a grant from Forest Laboratories, Inc (now Allergen).

\section{Conflict of interest}

G.E.S. received a research grant from Forest Laboratories, Inc (now Allergen) to conduct this investigation. None of the other authors have anything to declare.

\section{References}

1. Musher DM, Thorner AR (2014) Community-acquired pneumonia. N Engl J Med 371 1619-1628.[Crossref]

2. Smith SB, Ruhnke GW, Weiss CH, Waterer GW, Wunderink RG (2014) Trends in pathogens among patients hospitalized for pneumonia from 1993 to 2011. JAMA Intern Med 174: 1837-1839.[Crossref]

3. Chertow DS, Memoli MJ (2013) Bacterial coinfection in influenza: a grand rounds review. JAMA 309: 275-282.[Crossref]

4. Mandell LA, Wunderink RG, Anzueto A, Bartlett JG, Campbell GD, et al. (2007) Infectious Diseases Society of America/American Thoracic Society consensus guidelines on the management of community-acquired pneumonia in adults. Clin Infect Dis 2: S27-S72.[Crossref]

5. Magill SS, Edwards JR, Beldavs ZG, Dumyati G, Janelle SJ, et al. (2014) Prevalence of antimicrobial use in US acute care hospitals. JAMA 312: 1438-1446.[Crossref]

6. Mendes RE, Sader HS, Flamm RK, Farrell DJ2, Jones RN (2015) Telavancin in vitro activity against a collection of methicillin-resistant Staphylococcus aureus isolates, including resistant subsets from the United States. Antimicrob Agents Chemother 59:1811-1814.[Crossref]

7. Karlowsky JA, Biedenbach DJ, Bouchillon SK,Iaconis JP, Reiszner E, et al. (2016) In vitro activity of ceftaroline against bacterial pathogens isolated from skin and soft tissue infections in Europe, Russia and Turkey in 2012: results from the Assessing Worldwide Antimicrobial Resistance Evaluation (AWARE) surveillance programme. J Antimicrob Chemother 71:162-169.[Crossref]

8. Saravolatz LD, Stein GE, Johnson LB (2011)Ceftaroline: a novel cephalosporin with activity against methicillin-resistant Staphylococcus aureus. Clin Infect Dis 52:11561163.[Crossref]

9. File TM Jr, Low DE, Eckburg PB, Talbot GH, Friedland HD, et al. (2010) Integrated analysis of FOCUS 1 and FOCUS 2: randomized, doubled-blinded, multicenter phase 3 trials of the efficacy and safety of ceftarolinefosamil versus ceftriaxone in patients with community-acquired pneumonia. Clin Infect Dis 51: 1395-1405.[Crossref]

10. Taboada M, Melnick D, Iaconis JP, Sun F, Zhong NS, et al. (2016)Ceftarolinefosami versus ceftriaxone for the treatment of community-acquired pneumonia: individual patient data meta-analysis of randomized controlled trials. J Antimicrob Chemother 71: 862-870.[Crossref]

11. Riccodene TA, Su SF, Rank D (2013) Single- and multiple-dose study to determine the safety, tolerability, and pharmacokinetics of ceftarolinefosamil in combination with avibactam in healthy subjects. Antimicrob Agents Chemother 57: 1496-1504.[Crossref]

12. Clinical and Laboratory Standards Institute (2012) Performance standards for antimicrobial susceptibility testing: twenty-second informational supplement M100-S22. Wayne, PA:CLSI. 
13. National Committee for Clinical Laboratory Standards (1999) Methods for determining bactericidal activity of antimicrobial agents: approved guideline M26-A. Wayne, PA: NCCLS.

14. Clinical and Laboratory Standards Institute (2014) Performance standards for antimicrobial susceptibility testing: twenty-fourth informational supplement M100-S24. Wayne, PA:CLSI.

15. Rodvold KA, Danziger LH, Gotfried MH (2003) Steady-state plasma and bronchopulmonary concentrations of intravenous levofloxacin and azithromycin in healthy adults. Antimicrob Agents Chemother 47: 2450-2457.[Crossref]

16. Chow AT, Fowler C, Williams RR, Morgan N, Kaminski S, et al. (2001) Safety and pharmacokinetics of multiple 750-milligram doses of intravenous levofloxacin in healthy volunteers. Antimicrob Agents Chemother 45: 2122-2125.[Crossref]

17. Van Wart SA, Forrest A, Khariton T,Rubino CM, Bhavnani SM, et al. (2013) Population pharmacokinetics of ceftaroline in patients with acute bacterial skin and skin structure infections or community-acquired bacterial pneumonia. J Clin Pharmacol 53:11551167.[Crossref]

18. Mac Gowan A, Rogers C, Bowker K (2000)The use of in vitro pharmacodynamics models of infection to optimize fluoroquinolone dosing regimens. J Antimicrob Chemother 46: 163-170.

19. Wright DH, Brown GH, Peterson ML, Rotschafer JC (2000) Application of fluoroquinolone pharmacodynamics. J Antimicrob Chemother 46: 669-683.[Crossref]

20. Lodise TP, Lomaestro BM, Drusano GL (2006) Application of antimicrobial pharmacodynamics concepts into clinical practice: focus on ß-lactam antibiotics. Pharmacotherapy 26: 1320-1332.

21. Zhanel GG, Rossnagel E, Nichol K, Cox L, Karlowsky JA, et al. (2011) Ceftarolinepharmacodynamicactivity versus community-associated and healthcareassociated methicillin-resistant Staphylococcus aureus, heteroresistant vancomycinintermediate $\mathrm{S}$. aureus, vancomycin-intermediate $\mathrm{S}$. aureus and vancomycin-resistant S. aureus using an in vitro model. J Antimicrob Chemother 66:1301-1305.[Crossref]

22. MacGowan AP, Noel AR, Tomaselli S, Bowker KE (2013) Pharmacodynamics of ceftaroline against Staphylococcus aureus studied in an in vitro pharmacokinetic model of infection. Antimicrob Agents Chemother 57:2451-2456.

23. MacVane SH, So W, Nicolau DP, Kuti JL (2014) In vitro activity of human-simulated epithelial lining fluid exposures of ceftaroline, ceftriaxone, and vancomycin against methicillin-susceptible and -resistant Staphylococcus aureus. Antimicrob Agents Chemother 58: 7520-7526.[Crossref]

24. Mueller M, de la Peña A, Derendorf H (2004) Issues in pharmacokinetics and pharmacodynamics of anti-infective agents: kill curves versus MIC. Antimicrob Agents Chemother 48: 369-377.[Crossref]

25. Sader HS, Flamm RK, Jones RN (2013) Antimicrobial activity of ceftaroline-avibactam tested against clinical isolates collected from U.S. medical centers in 2010-2011. Antimicrob Agents Chemother 57: 1982-1988.

26. Polenakorik HM, Pleiman CM (2013) Ceftaroline for methicillin-resistan Staphylococcus aureus bacteremia: case series and review of the literature. Intern $J$ Antimirob Agents 42: 450-455.

Copyright: (C2016 Stein GE. This is an open-access article distributed under the terms of the Creative Commons Attribution License, which permits unrestricted use, distribution, and reproduction in any medium, provided the original author and source are credited. 